\title{
Cardiac Manifestations of Multisystem Inflammatory Syndrome in Children (MIS-C) Associated with SARS-CoV-2 Infection
}

\author{
Alireza Ghodsi (iD) ${ }^{1}$, Elnaz Mahmoudabadi ${ }^{1}$, Sara Ghahremani (iD) ${ }^{2}$ and Abdolreza Malek (iD ${ }^{2,}{ }^{*}$ \\ ${ }^{1}$ Student Research Committee, Faculty of Medicine, Mashhad University of Medical Sciences, Mashhad, Iran \\ ${ }^{2}$ Department of Pediatrics, Faculty of Medicine, Mashhad University of Medical Sciences, Mashhad, Iran \\ "Corresponding author: Department of Pediatrics, Faculty of Medicine, Mashhad University of Medical Sciences, Mashhad, Iran. Email: malekar@mums.ac.ir
}

Received 2020 October 04; Revised 2020 December 24; Accepted 2020 December 28.

\begin{abstract}
Context: Multisystem inflammatory syndrome in children (MIS-C) is an emerging condition after the spread of the severe acute respiratory syndrome coronavirus 2 (SARS-CoV-2) pandemic, termed COVID-19. This study aimed to describe the cardiac manifestations of children diagnosed with MIS-C.

Evidence Acquisition: This narrative review was conducted by searching the PubMed, Scopus, and Google Scholar databases to review MIS-C cardiac manifestations up to September 30, 2020. The demographic features, past medical history, clinical signs and symptoms, cardiac involvement, and the type of COVID-19 diagnosis confirmation were extracted.

Results: In many children, MIS-C seems to be a post-infectious complication of the COVID-19 infection. This syndrome affects multiple organs and has various clinical manifestations mimicking Kawasaki disease. Patients frequently present with persistent fever, kidney injury, gastrointestinal (GI) problems, neurologic symptoms, mucosal changes, conjunctivitis, and cardiac involvement. Children with MIS are more likely to present with hypotension, shock, and cardiac dysfunction, rather than coronary artery abnormalities and arrhythmia. Children with MIS need close observation; some need to be hospitalized, and a few may need a Pediatric Intensive Care Unit (PICU) admission. Treatment currently includes anticoagulants, IV immunoglobulin, and anti-inflammatory drugs.

Conclusions: As a novel syndrome associated with SARS-CoV-2 infection, MIS-C is potentially lethal. Cardiac manifestations, including coronary and myocardial involvement, are common and should be carefully identified. With prompt diagnosis and proper treatment, most children will survive, but the outcomes of the disease are unknown, so long-term follow-ups are required.
\end{abstract}

Keywords: Multisystem Inflammatory Syndrome in Children, COVID-19, SARS-CoV-2, Cardiac Involvement

\section{Context}

The SARS-CoV-2 infection, termed COVID-19, has spread very quickly and affected all ages, even newborns $(1,2)$. Initially, there was a misconception among the researchers believing that the virus does not affect children. However, it was then proposed that children are usually asymptomatic or present mild symptoms, but a complete immunity cannot be proposed for this age group (3). Since late April 2020, multiple studies from Europe and the United States showed that $2 \%$ - $6 \%$ of SARS-CoV-2-infected children exhibited a severe multi-system inflammatory syndrome with similarities to Kawasaki disease (4-6).

As there is no comprehensive testing, the true incidence of this severe condition in pediatrics has remained unclear. This significant hyper-inflammatory response can cause cardiovascular disorders, and some of these children may deteriorate faster and need admission to the Pediatric Intensive Care Unit (PICU) due to cardiogenic shock or acute left ventricular dysfunction (7). Apart from cardiac manifestations, various clinical symptoms have also been reported, including neurological, renal, significant gastrointestinal (GI), and mild respiratory symptoms, as well as rashes and stomatitis (8). Although it is still not fully understood whether this multisystem inflammatory syndrome in children (MIS-C) is a primary complication of COVID-19 infection or a post-infectious complication, a correlation is highly suggestive based on epidemiologic data (7).

There is little information about the cardiac involvement associated with COVID-19 in pediatric cases, and most of the studies on cardiac involvement are case reports or case series. It is also possible that children with an underlying cardiac disease are at a higher risk of experiencing 
severe cardiac complications following the COVID-19 infection (9). Reports on MIS-C have shown coronary artery involvement, myocarditis, ventricular dysfunction, hemodynamic instability, and PICU admission, all of which suggest that cardiac dysfunction might be a notable risk factor for severe SARS-CoV-2 infection in pediatrics (10). Therefore, a literature review in this regard would be beneficial. This study aimed to review and summarize the available evidence on the potential cardiac clinical presentations in children with MIS to give a better perspective on management and care for these patients.

It should be noted that different terms have been used to refer to this novel condition, such as multisystem inflammatory syndrome in children (MIS-C), hyperinflammatory shock in children with COVID-19, "Coronasacki”, "Kawashocky”, Pediatric COVID-19-associated inflammatory disorder (PCAID), and pediatric multisystem inflammatory syndrome (PMIS) (7). In this review article, we continue to use the term MIS-C.

\section{Methods}

A literature review was conducted by searching PubMed, Scopus, and Google Scholar. The following keywords were used for the search: "Pediatrics", "children", "heart”, "cardiac”, "Coronavirus disease-19”, “COVID19”, "SARS-CoV-2", "systemic inflammatory response syndrome", "multisystem inflammatory disorder in children and adolescents", "MISC", "PMIS", "PCAID”, "Coronasacki”, and "Kawashocky". We included case reports and case series related to MIS-C associated with SARS-CoV-2 infection. The inclusion criterion was defined as being a case report or case series reporting some findings of cardiac involvement in pediatrics with COVID-19. Articles published in languages other than English and those irrelevant to our objectives, like commentaries, other reviews, and letters to editors, were excluded. The last search was performed on September 30, 2020. We used the Newcastle-Ottawa scale (NOS) (11) for the quality assessment of the studies, and those with top quality were enrolled. The baseline data including the first author's name of the article, number of cases, age, sex, past medical history, ethnicity, clinical signs and symptoms, and the type of COVID-19 diagnosis confirmation (PCR or serology) were extracted. Moreover, the laboratory, electrocardiography, and echocardiography findings were gathered.

\section{Definition of MIS-C}

The three definitions of MIS-C, by the World Health Organization (WHO) (12), the Centers for disease control and prevention (CDC) (13), and the Royal College of Pediatrics and Child Health (RCPCH) (14), are presented in Table 1. The presence of fever, multisystem organ involvement without alternative plausible diagnoses, laboratory evidence of inflammation, and recent exposure to a COVID-19 case or evidence of COVID-19 infection are the key elements in all MIS$\mathrm{C}$ cases. But, some signs, including fever duration and organ involvement, vary among these criteria.

\section{Clinical Manifestation}

The available information regarding the syndrome shows that the age of patients ranged from two months to 20 years, and the majority of cases were previously healthy $(15,16)$. Almost all affected children had a persistent fever for $\geq 4$ days and GI symptoms, including abdominal pain, diarrhea, and vomit. Other common clinical manifestations were mucocutaneous changes resembling Kawasaki disease (skin rash and conjunctivitis), extremity edema, lymphadenopathy, headache, mild respiratory distress, myalgia, fatigue, and cardiac symptoms (Table 2). Some patients presented with shock and hypotension requiring PICU admission $(17,18)$. The cardiac findings in MIS$\mathrm{C}$ patients are divergent from Kawasaki disease's manifestations. Children with this syndrome were more likely to present with hypotension, shock, and cardiac dysfunction, rather than coronary artery abnormalities (Figure 1) (19).

\section{COVID-19 Infection}

Epidemiological information indicates that SARS-CoV2 is the possible cause of the syndrome, but the causality is unknown (1). Based on the studies mentioned in Table 2 , the positivity percentage of the COVID-19 reversetranscriptase protein chain reaction (RT-PCR) test varies from $0 \%$ to $100 \%$. In most reports, it was positive in less than $50 \%$ of cases. On the other hand, the majority of the studies had evidence of positive immunoglobulin G (IgG) antibodies. These data suggest that a post-infectious disease is more likely to be responsible for this condition than an active infection (44).

\section{Cardiac Involvement}

\subsection{Cardiac Dysfunction}

In most cases diagnosed with MIS-C, left ventricular systolic dysfunction has been reported (Table 2). In the first 


\begin{tabular}{|c|c|c|c|}
\hline & WHO & CDC & $\begin{array}{l}\text { NHS-the Royal College of Pediatrics } \\
\text { and Child Health }\end{array}$ \\
\hline Age (years) & $0-19$ & $<21$ & Children \\
\hline Fever & Fever $\geq 3$ days & $\begin{array}{l}\text { Subjective persistent fever } \geq 24 \text { hours } \\
\text { or documented fever }>38.0^{\circ} \mathrm{C} \text { for } \geq \\
24 \text { hours }\end{array}$ & Persistent fever $>38.5^{\circ} \mathrm{C}$ \\
\hline Clinical findings & $\begin{array}{l}\text { Mucocutaneous inflammation signs } \\
\text { (e.g., stomatitis), bilateral } \\
\text { non-purulent conjunctivitis or rash, } \\
\text { shock or hypotension, ventricular } \\
\text { dysfunction, valvulitis, pericarditis, or } \\
\text { coronary involvement (including an } \\
\text { increased level of NT-proBNP } \\
\text { /troponin or echo findings), acute GI } \\
\text { manifestations, including abdominal } \\
\text { pain, diarrhea, or vomiting }\end{array}$ & $\begin{array}{l}\text { Evidence of clinical deterioration } \\
\text { requiring hospital admission, in } \\
\text { addition to multiple }(\geq 2) \text { organ } \\
\text { dysfunction (renal, dermatologic, } \\
\text { cardiovascular, respiratory, GI, } \\
\text { hematologic, or neurologic) }\end{array}$ & $\begin{array}{l}\text { Single or multi-organ dysfunction } \\
\text { (cardiovascular, respiratory, renal, GI, } \\
\text { hematologic, dermatologic, or } \\
\text { neurologic). Oxygen requirement and } \\
\text { hypotension have been reported in } \\
\text { most kids. Other features, including } \\
\text { abdominal pain, diarrhea, vomiting, } \\
\text { conjunctivitis, rash, sore throat, } \\
\text { cough, respiratory symptoms, } \\
\text { headache, confusion, } \\
\text { lymphadenopathy, stomatitis, neck } \\
\text { swelling, hands and feet edema, } \\
\text { syncope have been seen in some } \\
\text { children. }\end{array}$ \\
\hline Laboratory findings & $\begin{array}{l}\text { Elevated inflammatory factors (e.g., } \\
\text { CRP, ESR, or procalcitonin) evidence of } \\
\text { coagulopathy in laboratory data (PT, } \\
\text { PTT, INR, and D-dimer) }\end{array}$ & $\begin{array}{l}\text { Elevated ESR, CRP, LDH, procalcitonin, } \\
\text { fibrinogen, D-dimer, ferritin, IL-6, } \\
\text { hypoalbuminemia neutrophilia; } \\
\text { lymphocytopenia }\end{array}$ & $\begin{array}{l}\text { Abnormal fibrinogen level, } \\
\text { hypoalbuminemia, high D-dimer and } \\
\text { ferritin amount Some: acute kidney } \\
\text { injury, anemia, coagulopathy, } \\
\text { thrombocytopenia, elevated IL-6, } \\
\text { elevated IL-10, hypertransaminasemia, } \\
\text { proteinuria, high troponin, increased } \\
\text { creatine kinase level, elevated } \\
\text { triglycerides, high LDH }\end{array}$ \\
\hline Evidence of COVID-19 infection & $\begin{array}{l}\text { Positive for SARS-CoV-2 infection by } \\
\text { serology, antigen test, or RT-PCR or } \\
\text { exposure to patients with COVID-19 } \\
\text { infection }\end{array}$ & $\begin{array}{l}\text { RT-PCR, or antigen test, or serology } \\
\text { positive for COVID-19 or possible } \\
\text { contact with COVID-19 patients within } \\
\text { a month before to the initiation of } \\
\text { clinical features }\end{array}$ & $\begin{array}{l}\text { SARS-CoV-2 RT-PCR testing may be } \\
\text { positive or negative }\end{array}$ \\
\hline Exclusion of other microbial causes & $\begin{array}{l}\text { Exclusion of any other infectious } \\
\text { causes of inflammation, including } \\
\text { toxic shock syndrome, bacterial sepsis, } \\
\text { staphylococcal or streptococcal } \\
\text { infections }\end{array}$ & $\begin{array}{l}\text { Exclusion of alternative plausible } \\
\text { diagnoses }\end{array}$ & $\begin{array}{l}\text { Exclusion of any other microbial } \\
\text { cause, including infectious } \\
\text { myocarditis, bacterial sepsis, and } \\
\text { staphylococcal/streptococcal toxic } \\
\text { shock syndromes }\end{array}$ \\
\hline Additional comments & $\begin{array}{l}\text { MIS-C must be considered in children } \\
\text { with characteristics of toxic shock } \\
\text { syndrome or typical or atypical } \\
\text { Kawasaki disease }\end{array}$ & $\begin{array}{l}\text { Consider MIS-C in any pediatric death } \\
\text { with evidence of COVID-19 infection. It } \\
\text { should be considered in children with } \\
\text { features of typical or atypical } \\
\text { Kawasaki disease who meet the case } \\
\text { definition for MIS-C }\end{array}$ & $\begin{array}{l}\text { Children may fulfill full or partial } \\
\text { criteria for Kawasaki disease }\end{array}$ \\
\hline
\end{tabular}

Abbreviations: APTT, activated partial thromboplastin time; COVID-19, coronavirus disease 2019; CRP, C-reactive protein, echo, echocardiography; CXR, chest X-ray; ESR, erythrocyte sedimentation rate; GI, gastrointestinal; IL, interleukin; LDH, lactic acid dehydrogenase; MIS-C, multisystem inflammatory syndrome in children; NT-proBNP, $\mathrm{N}$-terminal pro-B-type natriuretic peptide; PT, prothrombin time; PTT, partial thromboplastin time; 2, RT-PCR, reverse transcriptase-polymerase chain reaction; SARS-CoV2 , severe acute respiratory syndrome coronavirus.

report of MIS-C, Riphagen et al. (24) found ventricular dysfunction in six out of eight cases. The majority of available studies in the literature also reported that ventricular dysfunction happens in up to $50 \%$ of MIS-C patients (Table $2)$. Two case series mentioned cardiac dysfunction as an inclusion criterion $(20,38)$. Belhadjer et al. (20) considered an acute LV failure (LV ejection fraction (LVEF) $<50 \%$ ), and Grimaud et al. considered cardiogenic/vasogenic shock as an inclusion criterion (38). The incidence rate of cardiogenic shock is much greater in this syndrome than in the Kawasaki disease (60\% vs. 7\%) (45). Matsubara et al. (46) found severe LV dysfunction in MIS-C patients. They suggested that the subclinical myocarditis might lead to ventricular dysfunction.

The pathophysiology of cardiac dysfunction in patients with this syndrome is not known. The possible causes of acute myocardial dysfunction following a COVID19 infection in adults include hypoxic injury, myocarditis, ischemic heart injury due to coronary artery disease, stress cardiomyopathy (Takotsubo), acute cor pulmonale, and systemic inflammatory response syndrome (SIRS) (4750). 


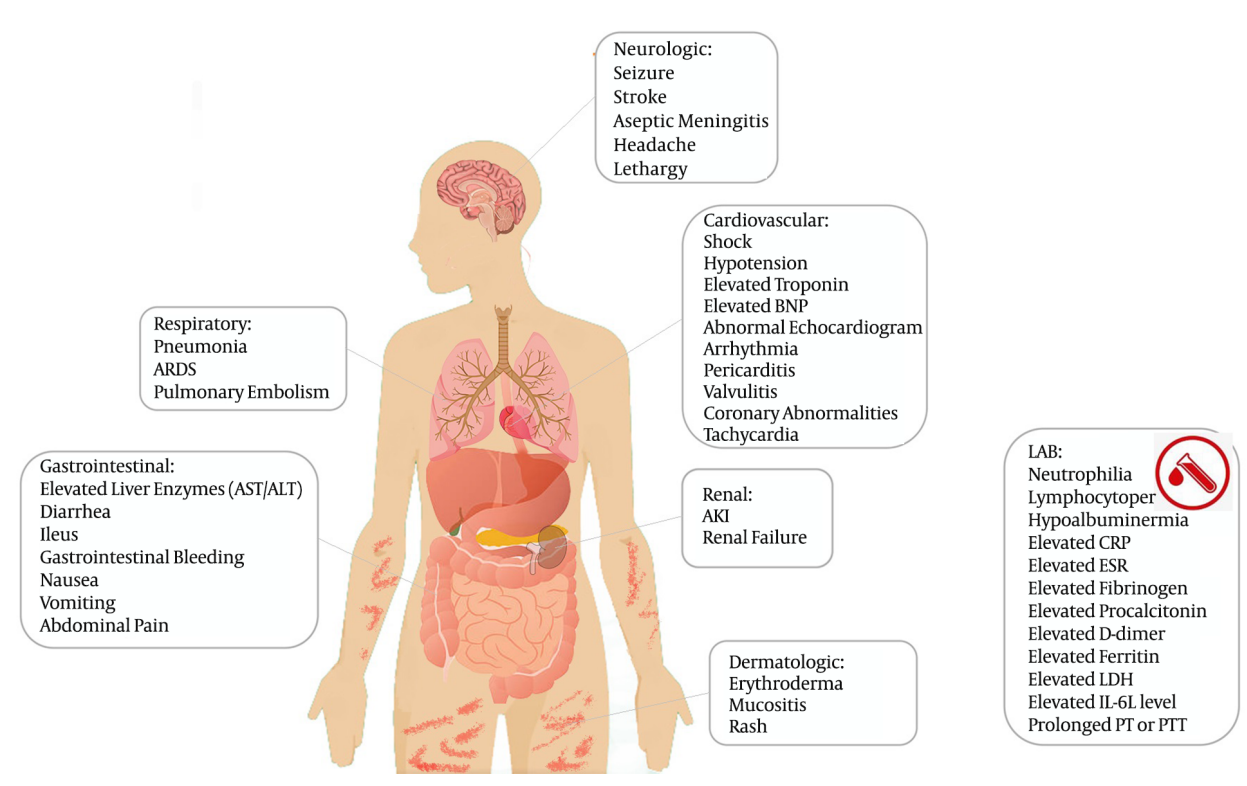

Figure 1. Schematic representation of clinical signs of MIS-C patients (both CDC and WHO criteria are shown)

\subsection{Laboratory Findings}

The elevated troponin and B-type natriuretic peptide (BNP)/pro-BNP levels have been reported in many patients with MIS-C. In most studies, the elevated BNP and troponin levels have been assessed as biomarkers to diagnose myocardial injury in the absence of cardiac magnetic resonance imaging (CMRI) or myocardial biopsies (15).

\subsection{Coronary Involvement}

Most reports have mentioned coronary involvement in $0-40 \%$ of cases (Table 2$)(16,21,24,26,41)$. Mild coronary artery dilation with z-scores of $2-2.5$ has been reported in most cases. However, large coronary artery aneurysm cases have also been mentioned. Some studies found the late development of coronary artery dilation, which necessitates an ongoing follow-up of MIS-C patients.

\subsection{ECG Findings}

Some case series reported rhythm abnormalities with variable severity in $4 \%-58 \%$ of patients (Table 2$)(18,22)$. The most frequently reported arrhythmic manifestations were QTC prolongation, ST-segment changes, and premature atrial or ventricular beats, which all are non-specific. Whittaker et al. (18) reported first- and second-degree atrioventricular blocks, and two other studies mentioned atrial fibrillation $(18,33)$. Hemodynamic collapse and the need for extracorporeal membrane oxygenation (ECMO) support due to sustained dysrhythmias have also been reported in these patients $(18,24)$.

\subsection{Management}

This syndrome is a newly reported condition, and only a few studies have addressed it so far. Our knowledge about it is, therefore, limited, and the treatment of children with MIS has been based on the experts' advice and the management of Kawasaki disease. Due to the similarity of the symptoms, the treatment method for adults with COVID19 and other systemic inflammatory diseases can also be used in pediatrics. Management of these children requires a multidisciplinary care team comprising pediatric specialists in cardiology, infectious disease, critical care, and rheumatology.

Generally, the management is decided based on symptoms and their severity. Due to the potential shortage of drug supplies in a pandemic and considering side effects, pharmacotherapy is not recommended for nonhospitalized children. For children who present with mild symptoms, supportive care, including respiratory support and fluid resuscitation, is, therefore, recommended. However, children with hemodynamic instability and severe illness require PICU admission, mostly for inotropic support, which was reported in 20-100\% of the cases (15-18, 20-22, 2427, 30-35, 37, 38). Some of the PICU-admitted children required a veno-arterial (V-A) support $(0 \%-28 \%)(15,17,18,20$, $24,30,33)$. 
Various treatments have been suggested, but their effectiveness is still questionable. Furthermore, these treatments are based on experts' opinions with no evidence to affirm them.

\subsection{Cardiac Support}

As mentioned above, a large proportion of children presenting with hemodynamic instability required acute resuscitation. Therefore, it is necessary to follow the pediatric resuscitation guidelines (51). Children suspicious of ventricular dysfunction and cardiogenic shock should receive smaller fluid blouses (e.g., $10 \mathrm{mg} / \mathrm{kg}$ ), with an evaluation of the signs of fluid overload before each administration.

\subsection{Immunomodulatory Therapy}

The advantages of using immunomodulatory therapy in the treatment of Kawasaki disease, as well as other systemic inflammatory disorders, are well established (52, 53). An anti-inflammatory therapy, including intravenous immunoglobulins (IVIGs) and corticosteroids, was used in most patients, and a few cases also received an antiinflammatory dosage of aspirin $(15,16,18,20-22,24,26,31$, $32,34-38$ ). It is critical to remember that the administration of IVIG in patients with cardiac dysfunction must be slower to reduce the risk of fluid overload. The dosage of corticosteroids is based on clinical judgment, but in more severe patients, using a low dosage is recommended.

The assessment of the pattern of cytokine storm in patients with MIS-C showed that an important component of this disorder is macrophage activation, as it is also observed in Kawasaki disease and other autoimmune disorders such as systemic lupus erythematosus $(35,54)$. Therefore, corticosteroids are another option in the treatment of MIS-C patients, as they can modulate this condition. However, corticosteroids may cause hypertension that can further exacerbate the underlying cardiac problem (45).

Two treatment protocols with corticosteroids have been proposed. The first method involves an intravenous injection of $0.8 \mathrm{mg} / \mathrm{kg}$ methylprednisolone, twice a day for 5 - 7 days or until achieving a normal CRP level and then continuing with oral treatment with $2 \mathrm{mg} / \mathrm{kg} /$ day for 2 - 3 weeks. The second protocol includes intravenous methylprednisolone 10 - $30 \mathrm{mg} / \mathrm{kg} /$ day for three days, followed by oral prednisone/prednisolone $2 \mathrm{mg} / \mathrm{kg} /$ day for four days or until achieving a normal CRP level and then tapering the treatment over 2 - 3 weeks. It is important to know that corticosteroids should not be administered in an active infection phase (1).
In some studies, cytokine blockers have been used as a supplemental therapy, for example, interleukin 1 receptor antagonist (e.g., anakinra), interleukin 6 (IL-6) inhibitors (e.g., tocilizumab), and tumor necrosis factor (TNF)- $\alpha$ inhibitors (e.g., infliximab) (16, 18, 20, 22-25, 27, 29-31, 34). These drugs can be prescribed for children who do not respond to routine treatments.

\subsection{Antiplatelet Treatment and Anticoagulation}

Hypercoagulable state, blood stasis due to immobilization, possible endothelial injury, and ventricular dysfunction are the proposed reasons for the increased risk of thrombotic complications. As a result, anticoagulant therapy should be considered based on coagulation tests and symptoms $(55,56)$.

\subsection{Antiviral Therapy}

The benefits of antiviral therapy, such as remdesivir, for children with this syndrome are still unknown $(57,58)$. The reports suggest that MIS-C is more likely a post-infectious complication in children rather than an active infection. Nonetheless, antiviral drugs could be considered in patients with a positive RT-PCR test, after consulting an infectious disease specialist.

\section{Conclusions}

In conclusion, children seem to proceed better with the novel coronavirus infection than adults. On the other hand, some children show signs and symptoms of MIS-C, which is a severe complication of the disease. Pediatricians should be aware of this syndrome and differentiate it from other differential diagnoses, including the Kawasaki disease. These children can quickly deteriorate and should closely be observed. The etiology of MIS-C is not yet fully understood, and treatment is mostly based on experts' opinions. More studies are, therefore, required to define evidence-based management for this new syndrome, and our study played a part in this literature contribution.

\section{Footnotes}

Authors' Contribution: All authors contributed to the study design, data collection, writing, and preparing this article.

Conflict of Interests: The authors declare no conflict of interest.

Funding/Support: The authors received no specific funding for this work. 


\section{References}

1. Nakra NA, Blumberg DA, Herrera-Guerra A, Lakshminrusimha S. Multi-System Inflammatory Syndrome in Children (MIS-C) Following SARS-CoV-2 Infection: Review of Clinical Presentation, Hypothetical Pathogenesis, and Proposed Management. Children (Basel). 2020;7(7). doi:10.3390/children7070069. [PubMed: 32630212]. [PubMed Central: PMC7401880].

2. Farhat AS, Sayedi SJ, Akhlaghi F, Hamedi A, Ghodsi A. Coronavirus (COVID-19) Infection in Newborns. Int J Pediatr. 2020;8(6):11513-7.

3. Ludvigsson JF. Systematic review of COVID-19 in children shows milder cases and a better prognosis than adults. Acta Paediatr. 2020;109(6):1088-95. doi: 10.1111/apa.15270. [PubMed: 32202343]. [PubMed Central: PMC7228328].

4. Dong Y, Mo X, Hu Y, Qi X, Jiang F, Jiang Z, et al. Epidemiology of COVID-19 Among Children in China. Pediatrics. 2020;145(6). doi: 10.1542/peds.2020-0702. [PubMed: 32179660].

5. Liguoro I, Pilotto C, Bonanni M, Ferrari ME, Pusiol A, Nocerino A, et al. SARS-COV-2 infection in children and newborns: a systematic review. Eur J Pediatr. 2020;179(7):1029-46. doi: 10.1007/s00431-020-03684-7. [PubMed: 32424745]. [PubMed Central: PMC7234446].

6. Sanna G, Serrau G, Bassareo PP, Neroni P, Fanos V, Marcialis MA. Children's heart and COVID-19: Up-to-date evidence in the form of a systematic review. Eur J Pediatr. 2020;179(7):1079-87. doi: 10.1007/s00431020-03699-0. [PubMed: 32474800]. [PubMed Central: PMC7261213].

7. Hennon TR, Penque MD, Abdul-Aziz R, Alibrahim OS, McGreevy MB, Prout AJ, et al. COVID-19 associated Multisystem Inflammatory Syndrome in Children (MIS-C) guidelines; a Western New York approach. Prog Pediatr Cardiol. 2020:101232. doi: 10.1016/j.ppedcard.2020.101232. [PubMed: 32837142]. [PubMed Central: PMC7244417].

8. Ghodsi A, Azarfar A, Ghahremani S. A Review of Coronavirus Disease (COVID-19) in Children.J Pediatr Nephrol. 2020;8(3).

9. Castagnoli R, Votto M, Licari A, Brambilla I, Bruno R, Perlini S, et al. Severe Acute Respiratory Syndrome Coronavirus 2 (SARS-CoV-2) Infection in Children and Adolescents: A Systematic Review. JAMA Pediatr. 2020;174(9):882-9. doi: 10.1001/jamapediatrics.2020.1467. [PubMed: 32320004].

10. Ghodsi A, Malek A, Ghahremani S. A Review of Multisystem Inflammatory Syndrome in Children (MIS-C) Associated with COVID-19. Hormozgan Med J. 2020;24(4). doi:10.5812/hmj.107048.

11. Wells GA, Shea B, O'Connell DA, Peterson J, Welch V, Losos M, et al. The Newcastle-Ottawa Scale (NOS) for assessing the quality of nonrandomised studies in meta-analyses. Oxford; 2000.

12. Labe P, Ly A, Sin C, Nasser M, Chapelon-Fromont E, Ben Said P, et al. Erythema multiforme and Kawasaki disease associated with COVID-19 infection in children. J Eur Acad Dermatol Venereol. 2020;34(10):e53941. doi: 10.1111/jdv.16666. [PubMed: 32455505]. [PubMed Central: PMC7283825].

13. Rivera-Figueroa EI, Santos R, Simpson S, Garg P. Incomplete Kawasaki Disease in a Child with Covid-19. Indian Pediatr. 2020;57(7):680-1. [PubMed: 32393680]. [PubMed Central: PMC7387257].

14. Raymond TT, Das A, Manzuri S, Ehrett S, Guleserian K, Brenes J. Pediatric COVID-19 and Pericarditis Presenting With Acute Pericardial Tamponade. World J Pediatr Congenit Heart Surg. 2020;11(6):802-4. doi: 10.1177/2150135120949455. [PubMed: 32909890]. [PubMed Central: PMC7484599].

15. Dufort EM, Koumans EH, Chow EJ, Rosenthal EM, Muse A, Rowlands J, et al. Multisystem Inflammatory Syndrome in Children in New York State. N Engl J Med. 2020;383(4):347-58. doi: 10.1056/NEJMoa2021756. [PubMed: 32598830]. [PubMed Central: PMC7346766].

16. Wolfler A, Mannarino S, Giacomet V, Camporesi A, Zuccotti G. Acute myocardial injury: a novel clinical pattern in children with COVID-
19. Lancet Child Adolesc Health. 2020;4(8):e26-7. doi: 10.1016/S23524642(20)30168-1. [PubMed: 32497521]. [PubMed Central: PMC7263818].

17. Feldstein LR, Rose EB, Horwitz SM, Collins JP, Newhams MM, Son $\mathrm{MBF}$, et al. Multisystem Inflammatory Syndrome in U.S. Children and Adolescents. N Engl J Med. 2020;383(4):334-46. doi: 10.1056/NEJMoa2021680. [PubMed: 32598831]. [PubMed Central: PMC7346765].

18. Whittaker E, Bamford A, Kenny J, Kaforou M, Jones CE, Shah P, et al. Clinical Characteristics of 58 Children With a Pediatric Inflammatory Multisystem Syndrome Temporally Associated With SARS-CoV2. JAMA. 2020;324(3):259-69. doi: 10.1001/jama.2020.10369. [PubMed: 32511692]. [PubMed Central: PMC7281356].

19. Shulman ST. Pediatric COVID-associated Multi-system Inflammatory Syndrome (PMIS). J Pediatr Infect Dis Soc. 2020.

20. Belhadjer Z, Meot M, Bajolle F, Khraiche D, Legendre A, Abakka S, et al. Acute Heart Failure in Multisystem Inflammatory Syndrome in Children in the Context of Global SARS-CoV-2 Pandemic. Circulation. 2020;142(5):429-36. doi: 10.1161/CIRCULATIONAHA.120.048360. [PubMed: 32418446].

21. Toubiana J, Poirault C, Corsia A, Bajolle F, Fourgeaud J, Angoulvant F, et al. Kawasaki-like multisystem inflammatory syndrome in children during the covid-19 pandemic in Paris, France: prospective observational study. BMJ.2020;369:m2094.doi:10.1136/bmj.m2094.[PubMed: 32493739]. [PubMed Central: PMC7500538].

22. Cheung EW, Zachariah P, Gorelik M, Boneparth A, Kernie SG, Orange JS, et al. Multisystem Inflammatory Syndrome Related to COVID-19 in Previously Healthy Children and Adolescents in New York City. JAMA. 2020;324(3):294-6. doi: 10.1001/jama.2020.10374. [PubMed: 32511676]. [PubMed Central: PMC7281352].

23. Dolinger MT, Person H, Smith R, Jarchin L, Pittman N, Dubinsky MC, et al. Pediatric Crohn Disease and Multisystem Inflammatory Syndrome in Children (MIS-C) and COVID-19 Treated With Infliximab. J Pediatr Gastroenterol Nutr. 2020;71(2):153-5. doi 10.1097/MPG.0000000000002809. [PubMed: 32452979]. [PubMed Central: PMC7268863].

24. Riphagen S, Gomez X, Gonzalez-Martinez C, Wilkinson N, Theocharis P. Hyperinflammatory shock in children during COVID-19 pandemic. Lancet. 2020;395(10237):1607-8. doi: 10.1016/S0140-6736(20)31094-1. [PubMed: 32386565]. [PubMed Central: PMC7204765].

25. Waltuch T, Gill P, Zinns LE, Whitney R, Tokarski J, Tsung JW, et al. Features of COVID-19 post-infectious cytokine release syndrome in children presenting to the emergency department. Am J Emerg Med.2020;38(10):2246 e3-6. doi:10.1016/j.ajem.2020.05.058. [PubMed: 32471782]. [PubMed Central: PMC7255141].

26. Licciardi F, Pruccoli G, Denina M, Parodi E, Taglietto M, Rosati S, et al. SARS-CoV-2-Induced Kawasaki-Like Hyperinflammatory Syndrome: A Novel COVID Phenotype in Children. Pediatrics. 2020;146(2). doi: 10.1542/peds.2020-1711. [PubMed: 32439816].

27. Borocco C, Pouletty M, Galeotti C, Meinzer U, Faye A, Kone-Paut I, et al. Response to 'Correspondence on 'Paediatric multisystem inflammatory syndrome temporally associated with SARS-CoV-2 mimicking Kawasaki disease (Kawa-COVID19): a multicentre cohort" by Mastrolia et al. Ann Rheum Dis. 2020. doi: 10.1136/annrheumdis-2020-218814. [PubMed: 33023959].

28. Jones VG, Mills M, Suarez D, Hogan CA, Yeh D, Segal JB, et al. COVID19 and Kawasaki Disease: Novel Virus and Novel Case. Hosp Pediatr. 2020;10(6):537-40. doi:10.1542/hpeds.2020-0123. [PubMed:32265235].

29. Balasubramanian S, Nagendran TM, Ramachandran B, Ramanan AV. Hyper-inflammatory Syndrome in a Child With COVID-19 Treated Successfully With Intravenous Immunoglobulin and Tocilizumab. Indian Pediatr. 2020;57(7):681-3. [PubMed: 32393681]. [PubMed Central: PMC7387261].

30. Kaushik S, Aydin SI, Derespina KR, Bansal PB, Kowalsky S, Trachtman R, et al. Multisystem Inflammatory Syndrome in Children Asso- 
ciated with Severe Acute Respiratory Syndrome Coronavirus 2 Infection (MIS-C): A Multi-institutional Study from New York City. J Pediatr. 2020;224:24-9. doi: 10.1016/j.jpeds.2020.06.045. [PubMed: 32553861]. [PubMed Central: PMC7293760].

31. Greene AG, Saleh M, Roseman E, Sinert R. Toxic shock-like syndrome and COVID-19: Multisystem inflammatory syndrome in children (MIS-C). Am J Emerg Med. 2020;38(11):2492 e5-6. doi: 10.1016/j.ajem.2020.05.117. [PubMed: 32532619]. [PubMed Central: PMC7274960].

32. Rauf A, Vijayan A, John ST, Krishnan R, Latheef A. Multisystem Inflammatory Syndrome with Features of Atypical Kawasaki Disease during COVID-19 Pandemic. Indian J Pediatr. 2020;87(9):745-7. doi: 10.1007/s12098-020-03357-1. [PubMed: 32462354].

33. Deza Leon MP, Redzepi A, McGrath E, Abdel-Haq N, Shawaqfeh A, Sethuraman U, et al. COVID-19-Associated Pediatric Multisystem Inflammatory Syndrome. J Pediatric Infect Dis Soc. 2020;9(3):407-8. doi: 10.1093/jpids/piaa061. [PubMed: 32441749]. [PubMed Central: PMC7313914].

34. Chiotos K, Bassiri H, Behrens EM, Blatz AM, Chang J, Diorio C, et al. Multisystem Inflammatory Syndrome in Children During the Coronavirus 2019 Pandemic: A Case Series. J Pediatric Infect Dis Soc. 2020;9(3):393-8. doi: 10.1093/jpids/piaa069. [PubMed: 32463092]. [PubMed Central: PMC7313950].

35. Verdoni L, Mazza A, Gervasoni A, Martelli L, Ruggeri M, Ciuffreda M, et al. An outbreak of severe Kawasaki-like disease at the Italian epicentre of the SARS-CoV-2 epidemic: an observational cohort study. Lancet. 2020;395(10239):1771-8. doi: 10.1016/S0140-6736(20)31103-X. [PubMed: 32410760]. [PubMed Central: PMC7220177].

36. Blondiaux E, Parisot P, Redheuil A, Tzaroukian L, Levy Y, Sileo C, et al. Cardiac MRI in Children with Multisystem Inflammatory Syndrome Associated with COVID-19. Radiology. 2020;297(3):E283-8. doi: 10.1148/radiol.2020202288. [PubMed: 32515676]. [PubMed Central: PMC7294821].

37. Ramcharan T, Nolan O, Lai CY, Prabhu N, Krishnamurthy R, Richter AG, et al. Paediatric Inflammatory Multisystem Syndrome: Temporally Associated with SARS-CoV-2 (PIMS-TS): Cardiac Features, Management and Short-Term Outcomes at a UK Tertiary Paediatric Hospital. Pediatr Cardiol. 2020;41(7):1391-401. doi: 10.1007/s00246-020-02391-2. [PubMed: 32529358]. [PubMed Central: PMC7289638].

38. Grimaud M, Starck J, Levy M, Marais C, Chareyre J, Khraiche D, et al. Acute myocarditis and multisystem inflammatory emerging disease following SARS-CoV-2 infection in critically ill children. Ann Intensive Care. 2020;10(1):69. doi: 10.1186/s13613-020-00690-8. [PubMed: 32488505]. [PubMed Central: PMC7266128].

39. Jain MK, Sahu SK, Behera JR, Patnaik S. Multisystem Inflammatory Syndrome in Children Associated with COVID 19 Treated with Oral Steroid. Indian J Pediatr. 2021;88(1):106. doi:10.1007/s12098-020-034974. [PubMed: 32930973]. [PubMed Central: PMC7490472].

40. Heidemann SM, Tilford B, Bauerfeld C, Martin A, Garcia RU, Yagiela L, et al. Three Cases of Pediatric Multisystem Inflammatory Syndrome Associated with COVID-19 Due to SARS-CoV-2. Am J Case Rep. 2020;21. e925779. doi: 10.12659/AJCR.925779. [PubMed: 32790652]. [PubMed Central: PMC7447294].

41. Alnashri H, Aljohani N, Tayeb S, Rabie N, AlBenayan E, Alharthi A, et al. A challenging case of multisystem inflammatory syndrome in children related to coronavirus Disease-19 hospitalized under adult medical service. IDCases. 2020;22. e00957. doi: 10.1016/j.idcr.2020.e00957. [PubMed: 32953455]. [PubMed Central: PMC7489252].

42. Torres JP, Izquierdo G, Acuna M, Pavez D, Reyes F, Fritis A, et al. Multisystem inflammatory syndrome in children (MIS-C): Report of the clinical and epidemiological characteristics of cases in Santiago de Chile during the SARS-CoV-2 pandemic. Int J Infect Dis. 2020;100:75-81. doi: 10.1016/j.ijid.2020.08.062. [PubMed: 32861823]. [PubMed Central:
PMC7452906].

43. Dolhnikoff M, Ferreira Ferranti J, de Almeida Monteiro RA, DuarteNeto AN, Soares Gomes-Gouvea M, Viu Degaspare N, et al. SARS-CoV-2 in cardiac tissue of a child with COVID-19-related multisystem inflammatory syndrome. Lancet Child Adolesc Health. 2020;4(10):790-4. doi: 10.1016/S2352-4642(20)30257-1. [PubMed: 32828177]. [PubMed Central: PMC7440866].

44. McCrindle BW, Manlhiot C. SARS-CoV-2-Related Inflammatory Multisystem Syndrome in Children: Different or Shared Etiology and Pathophysiology as Kawasaki Disease? JAMA. 2020;324(3):246-8. doi: 10.1001/jama.2020.10370. [PubMed: 32511667].

45. Rodriguez-Gonzalez M, Castellano-Martinez A, Cascales-Poyatos HM, Perez-Reviriego AA. Cardiovascular impact of COVID-19 with a focus on children: A systematic review. World J Clin Cases. 2020;8(21):525083. doi: 10.12998/wjcc.v8.i21.5250. [PubMed: 33269260]. [PubMed Central: PMC7674714].

46. Matsubara D, Kauffman HL, Wang Y, Calderon-Anyosa R, Nadaraj $\mathrm{S}$, Elias MD, et al. Echocardiographic Findings in Pediatric Multisystem Inflammatory Syndrome Associated With COVID-19 in the United States. J Am Coll Cardiol. 2020;76(17):1947-61. doi: 10.1016/j.jacc.2020.08.056. [PubMed: 32890666]. [PubMed Central: PMC7467656].

47. Shi S, Qin M, Shen B, Cai Y, Liu T, Yang F, et al. Association of Cardiac Injury With Mortality in Hospitalized Patients With COVID-19 in Wuhan, China. JAMA Cardiol. 2020;5(7):802-10. doi: 10.1001/jamacardio.2020.0950. [PubMed: 32211816]. [PubMed Central: PMC7097841].

48. Creel-Bulos C, Hockstein M, Amin N, Melhem S, Truong A, Sharifpour M. Acute Cor Pulmonale in Critically Ill Patients with Covid-19. N Engl J Med. 2020;382(21). e70. doi: 10.1056/NEJMc2010459. [PubMed: 32374956]. [PubMed Central: PMC7281714].

49. Zheng YY, Ma YT, Zhang JY, Xie X. COVID-19 and the cardiovascular system. Nat Rev Cardiol. 2020;17(5):259-60. doi:10.1038/s41569-020-03605. [PubMed: 32139904]. [PubMed Central: PMC7095524].

50. Tersalvi G, Vicenzi M, Calabretta D, Biasco L, Pedrazzini G, Winterton D. Elevated Troponin in Patients With Coronavirus Disease 2019: Possible Mechanisms. J Card Fail. 2020;26(6):470-5. doi: 10.1016/j.cardfail.2020.04.009. [PubMed: 32315733]. [PubMed Central: PMC7166030].

51. Edelson DP, Sasson C, Chan PS, Atkins DL, Aziz K, Becker LB, et al. Interim Guidance for Basic and Advanced Life Support in Adults, Children, and Neonates With Suspected or Confirmed COVID-19: From the Emergency Cardiovascular Care Committee and Get With The Guidelines-Resuscitation Adult and Pediatric Task Forces of the American Heart Association. Circulation. 2020;141(25):e933-43. doi: 10.1161/CIRCULATIONAHA.120.047463. [PubMed: 32270695]. [PubMed Central: PMC7302067].

52. Pineton de Chambrun M, Luyt CE, Beloncle F, Gousseff M, Mauhin W, Argaud L, et al. The Clinical Picture of Severe Systemic CapillaryLeak Syndrome Episodes Requiring ICU Admission. Crit Care Med. 2017;45(7):1216-23. doi: 10.1097/CCM.0000000000002496. [PubMed: 28622216].

53. Thompson PD, Myerburg RJ, Levine BD, Udelson JE, Kovacs RJ. Eligibility and disqualification recommendations for competitive athletes with cardiovascular abnormalities: task force 8: coronary artery disease: a scientific statement from the American Heart Association and American College of Cardiology. Circulation. 2015;132(22):e310-e4. doi: 10.1161/CIR.0000000000000244.

54. Ravelli A, Minoia F, Davi S, Horne A, Bovis F, Pistorio A, et al. 2016 Classification Criteria for Macrophage Activation Syndrome Complicating Systemic Juvenile Idiopathic Arthritis: A European League Against Rheumatism/American College of Rheumatology/Paediatric Rheumatology International Trials Organisation Collaborative Initia- 
tive. Ann Rheum Dis. 2016;75(3):481-9. doi: 10.1136/annrheumdis-2015208982. [PubMed: 26865703].

55. Wright FL, Vogler TO, Moore EE, Moore HB, Wohlauer MV, Urban S, et al. Fibrinolysis Shutdown Correlation with Thromboembolic Events in Severe COVID-19 Infection. J Am Coll Surg. 2020;231(2):193203 e1. doi: 10.1016/j.jamcollsurg.2020.05.007. [PubMed: 32422349]. [PubMed Central: PMC7227511].

56. Raval JS, Burnett AE, Rollins-Raval MA, Griggs JR, Rosenbaum L, Nielsen ND, et al. Viscoelastic testing in COVID-19: a possible screening tool for severe disease? Transfusion. 2020;60(6):1131-2. doi: 10.1111/trf.15847. [PubMed: 32374920]. [PubMed Central: PMC7267656]. 57. Beigel JH, Tomashek KM, Dodd LE, Mehta AK, Zingman BS, Kalil AC, et al. Remdesivir for the Treatment of Covid-19 - Final Report. N Engl J Med. 2020;383(19):1813-26. doi: 10.1056/NEJMoa2007764. [PubMed: 32445440]. [PubMed Central: PMC7262788].

58. Goldman JD, Lye DCB, Hui DS, Marks KM, Bruno R, Montejano R, et al. Remdesivir for 5 or 10 Days in Patients with Severe Covid-19. N Engl J Med. 2020;383(19):1827-37. doi: 10.1056/NEJMoa2015301. [PubMed: 32459919]. [PubMed Central: PMC7377062]. 


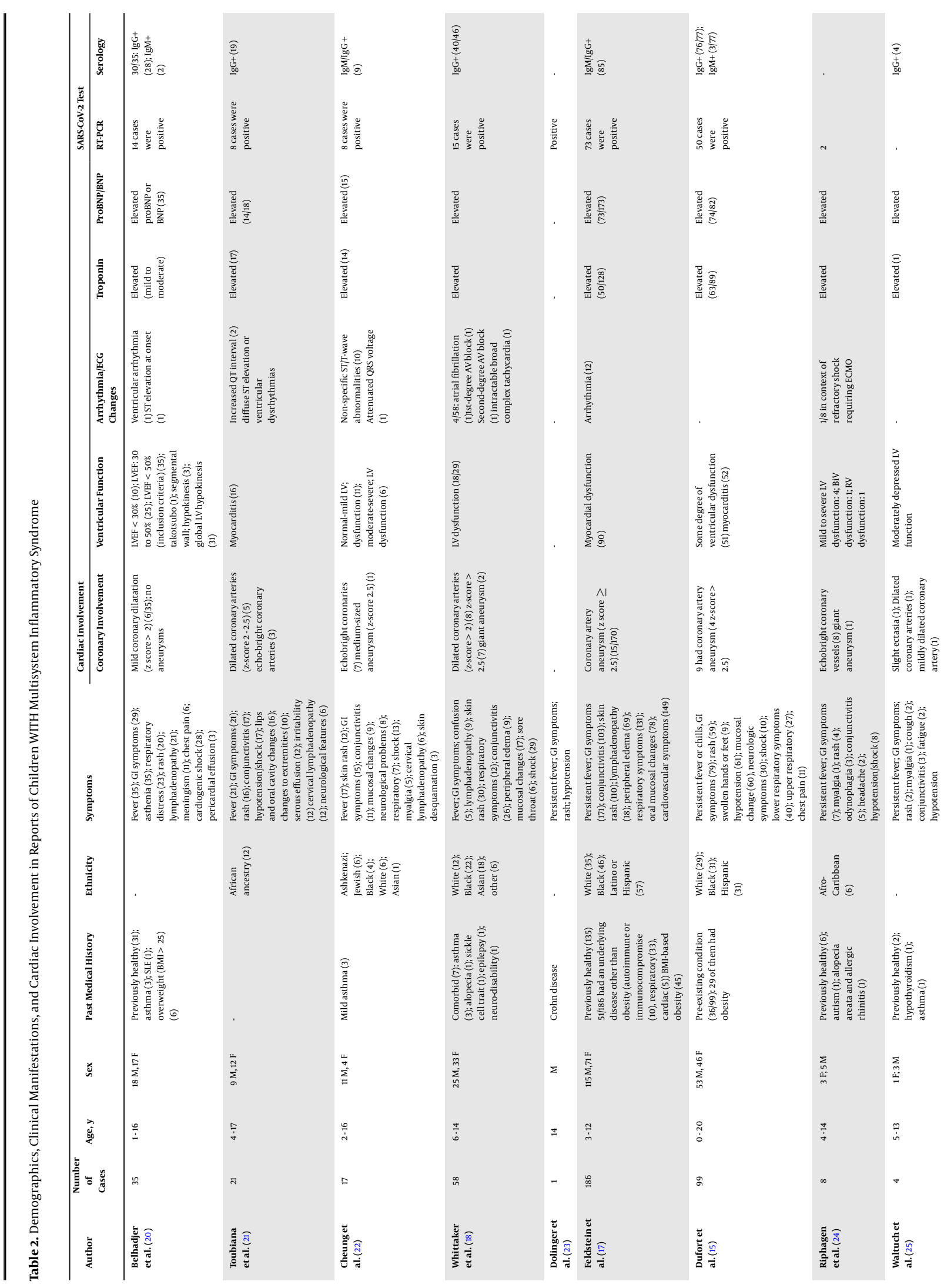




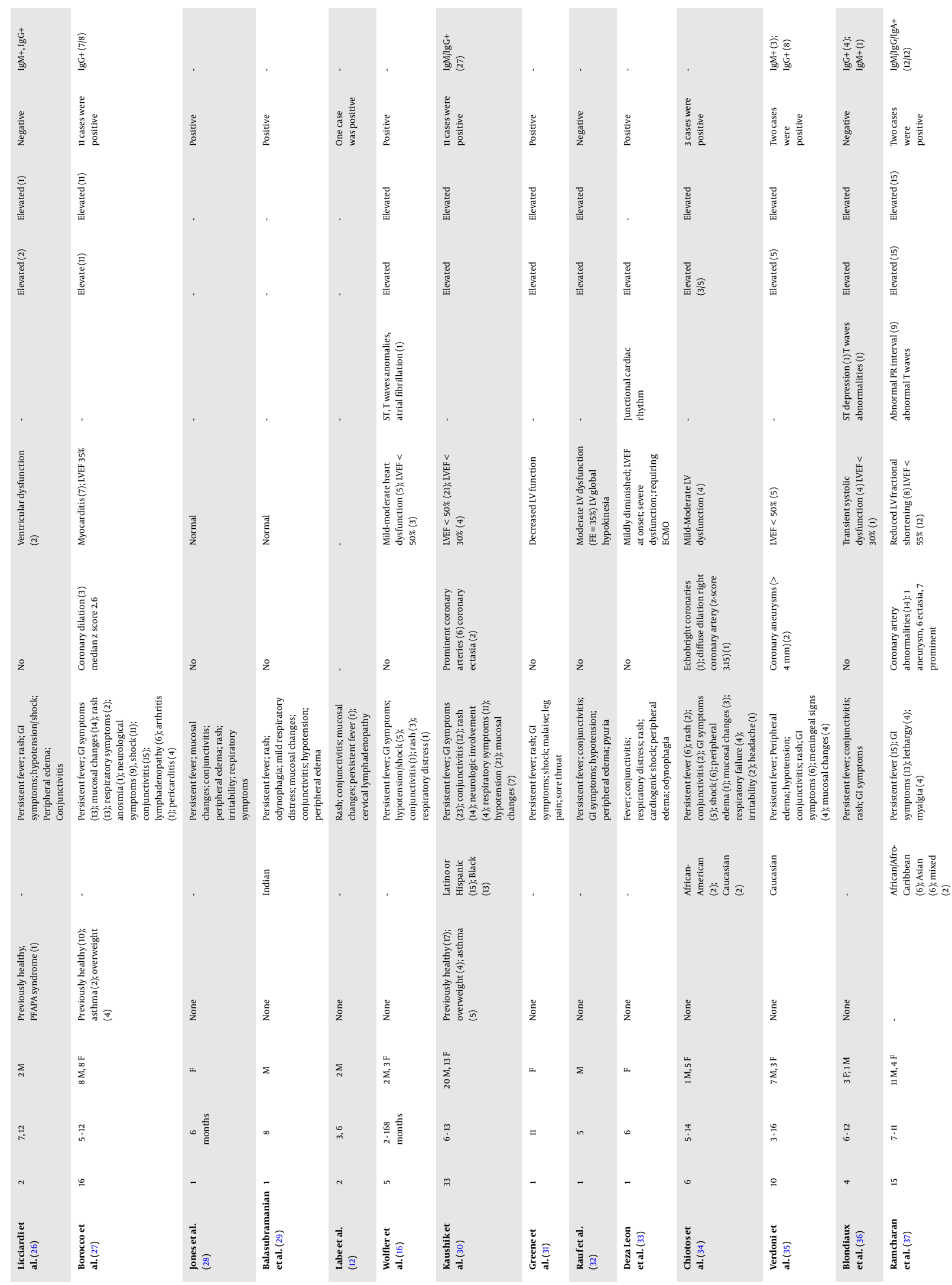




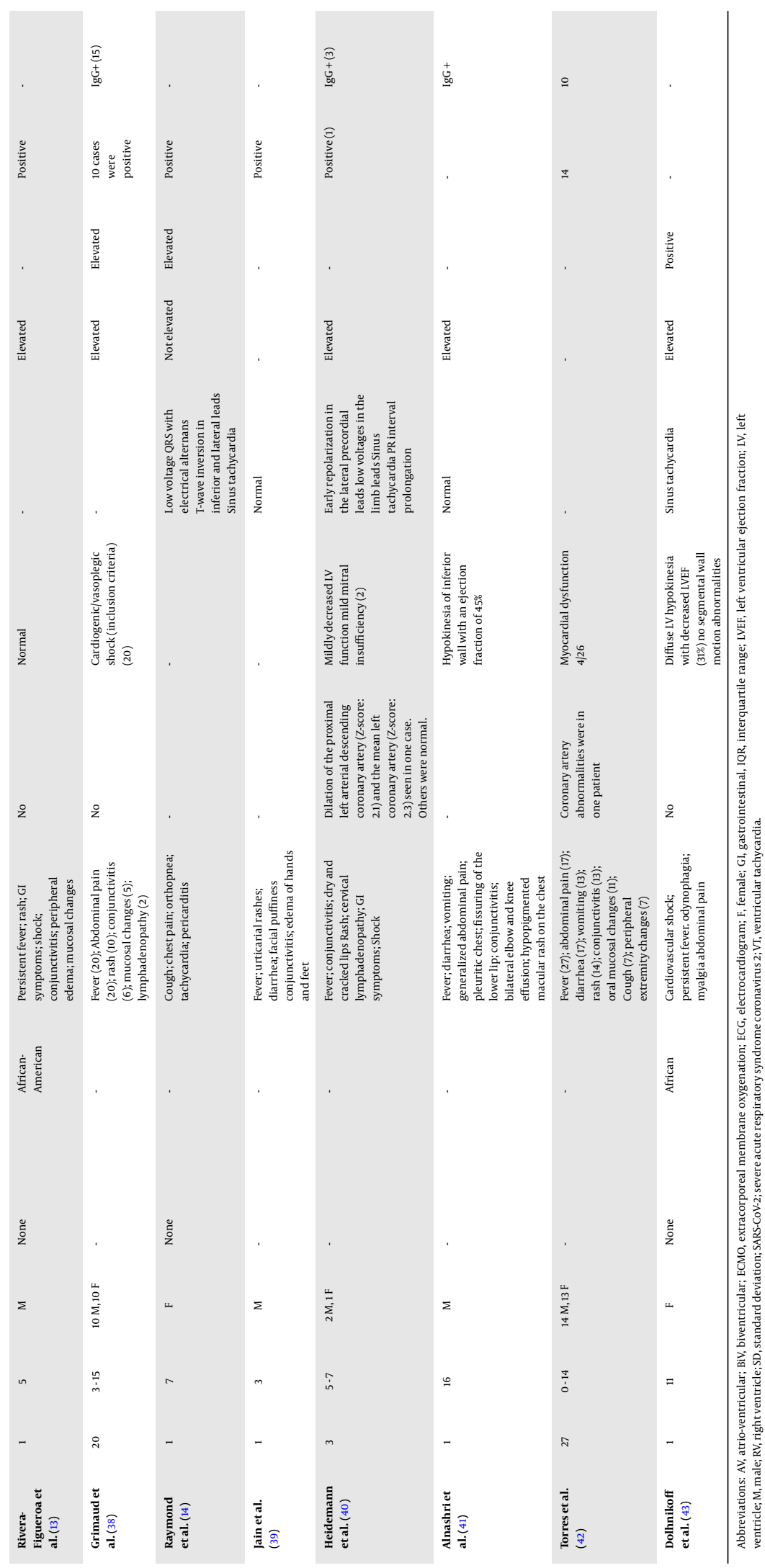

